Portland State University

PDXScholar

1980

\title{
Individual differences in imaginal and verbal information processing abilities
}

Joan Marie Anderson

Portland State University

Follow this and additional works at: https://pdxscholar.library.pdx.edu/open_access_etds

Part of the Cognition and Perception Commons

Let us know how access to this document benefits you.

\section{Recommended Citation}

Anderson, Joan Marie, "Individual differences in imaginal and verbal information processing abilities" (1980). Dissertations and Theses. Paper 3010.

https://doi.org/10.15760/etd.2987

This Thesis is brought to you for free and open access. It has been accepted for inclusion in Dissertations and Theses by an authorized administrator of PDXScholar. Please contact us if we can make this document more accessible: pdxscholar@pdx.edu. 
AN ABSTRACT OF THE THESIS OF Joan Marie Anderson for the Master of Science in Psychology presented July 18, 1980.

Title: Individual Differences in Imaginal and Verbal Information Processing Abilities.

APPROVED BY MEMBERS OF THE THESIS COMMITTEE:

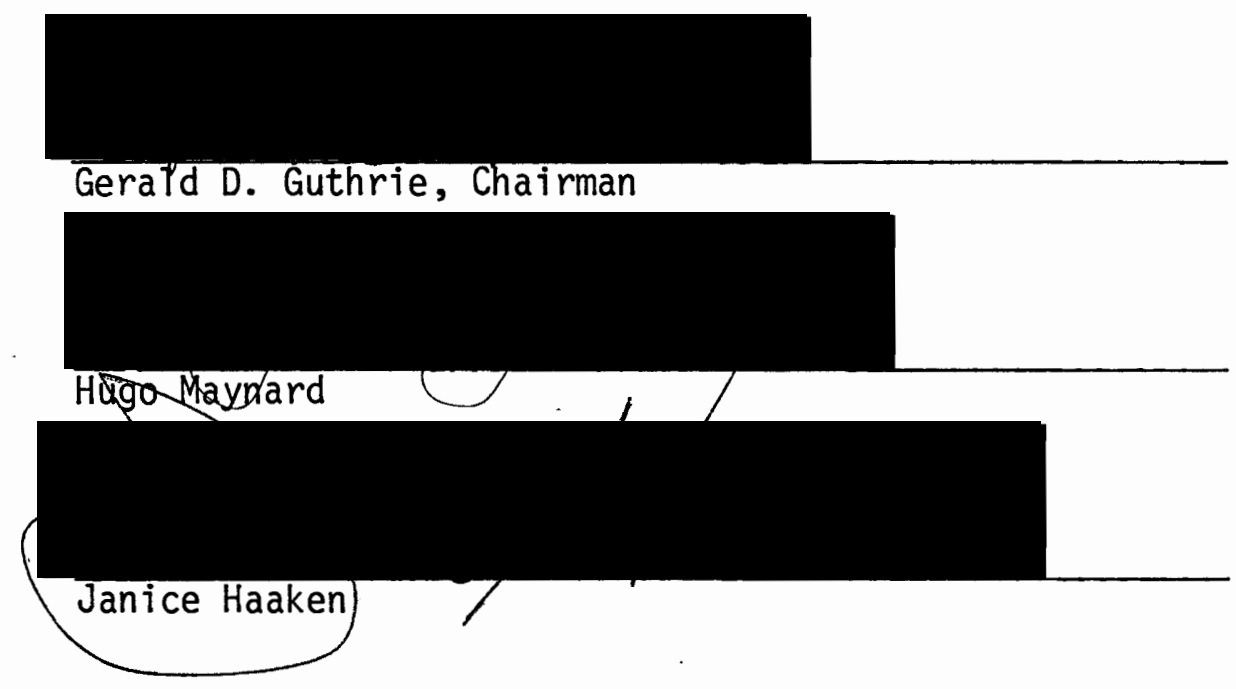

The present research is based on the theory that there are two major modes of consciousness, verbal and imaginal, which are controlled by the left and right hemispheres, respectively. This project was concerned with the relationship between these modes of consciousness and the measures employed in this study. The measures employed were an ongoing mentation report (OMR), a paired-associate learning (PAL) task, the Betts vividness of imagery questionnaire, the Gordon test of imagery control, and the visual imagery scale of Imaginal Processes Inventory (IPI). EEG and EOG measures were recorded during the OMR, and latera1 
eye movement was taken as an indication of activation in the cerebral hemisphere contralateral to the direction of eye movement.

The first hypothesis, that the type of OMR report would correspond with hemisphere activation (perceptual report with left eye movement and conceptual report with right eye movement), was not supported. The second hypothesis concerned recall of concrete and abstract nouns on the PAL task. The prediction that imagers would perform superior to verbalizers on trial II (concrete/imagery) and that verbalizers would perform superior to imagers on trial III (abstract/verbal), was not supported. In fact, imagers recalled significantly more of the abstract words on trial III than the verbalizers. The last hypothesis predicted correlations between the three self-report measures of imagery (Betts, Gordon, and IPI) with rated vividness on the OMR reports. OMR reports were found to correlate significantly with the IPI scale of visual imagery, but not with the Betts or Gordon tests. It was concluded that these measures were tapping different aspects of the imagery process. 
INDIVIDUAL DIFFERENCES IN IMAGINAL AND VERBAL

INFORMATION PROCESSING ABILITIES

\author{
by \\ JOAN MARIE ANDERSON
}

A thesis submitted in partial fulfillment of the requirements for the degree of

\author{
MASTER OF SCIENCE \\ in \\ PSYCHOLOGY
}

Portland State University

1980 
TO THE OFFICE OF GRADUATE STUDIES AND RESEARCH:

The members of the Committee approve the thesis of Joan Marie Anderson presented Jụy 18, 1980.

Gerald D. Guthrie, Chairman

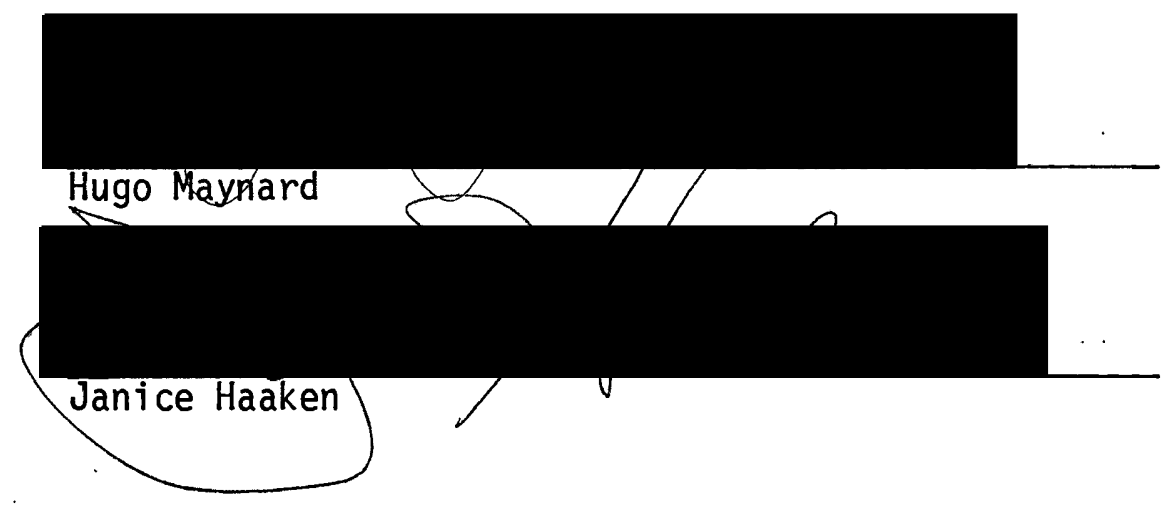

APPROVED:

Robert E. Jones, Jr., Head, Department of Psychology

Stanley E. Rauch, Dean of Graduate Studies and Research 
TABLE OF CONTENTS

PAGE

LIST OF TABLES . . . . . . . . . . . . . .

CHAPTER

I INTRODUCTION ............................ 1

II SEVERAL RELATED THEORIES OF CONSCIOUSNESS ...... 3

III TWO MODES OF CONSCIOUSNESS ............. . . 7

Theoretical Models............ . 7

Empirical Evidence........... 10

IV IMAGERY AND VERBAL PROCESSES . . . . . . . . . . 13

Functional Distinctions ......... 13

Empirical Approach ............ 15

$\checkmark$ DESCRIPTION OF THE PRESENT STUDY . . . . . . . . 22

Statement of Purpose .......... 22

Method .............. 23

Subjects

Procedures

VI RESULTS .......................... 33

VII DISCUSSION . . . . . . . . . . . . . . 37

VIII IMPLICATIONS FOR FUTURE RESEARCH .......... 43

REFERENCES ....................... 
PAGE

APPENDICES .............................. 51

A RATING SCALE FOR VIVIDNESS . . . . . . . . 52

B ORIENTATION SCRIPT-OMR ............ 53

C INTERVIEW--OMR . . . . . . . . . . . . . 55

D PAL INSTRUCTIONS ........................ 56

E PAL WORD LIST . . . . . . . . . . . . 57

F PAL QUESTIONNAIRE ..................... 58

G BETTS QUESTIONNAIRE ....................... 59

H GORDON TEST ................................. 63

I IPI SUBSCALES ...................... 65 


\section{LIST OF TABLES}

TABLE

PAGE

I Subject-by-subject Analys is of Classification by

Eye Movement as Compared with Classification

by Type of Report . . . . . . . . . . .

II Report-by-report Comparison of Eye Movements by

Type of Report . . . . . . . . . . .

III Means and Standard Deviations for Imagers and

Verbalizers on Trials II and III of the

PAL Task . . . . . . . . . . . . . .

IV Means and Standard Deviations for OMR, IPI, Betts, and Gordon .................. .

$\checkmark$ Breakdown of Males and Females According to

Classifications by Type of Report and by

Eye Movement Direction . . . . . . . . . . 


\section{CHAPTER I}

\section{INTRODUCTION}

One of the most perplexing and enduring questions for man concerns the problem of consciousness: its nature and function. This problem has woven its way through history and is once again the focus of current research (Deikman, 1971; Jaynes, 1976; Ornstein, 1972; Tart, 1972; Tomkins, 1962). The present research project begins with an introduction to several related theories of consciousness, followed by a distinction between individuals in the way consciousness is experienced on both a psychological and a physiological level. Individuals differ in the extent to which they employ verbal or imaginal processes as symbolic habits. Symbolic habits (modes) are ways we process data and represent that information in consciousness. The verbal mode processes information in a linear way. The imaginal mode processes information in a nonlinear, holistic way.

The main theme to emerge from the literature review is that there appear to be two major modes of consciousness--verbal and imaginal-which are controlled by the left and right hemispheres, respectively. This project was concerned with differentiating between verbal and imaginal habits and correlating the two modes with several tasks. The measures employed for this purpose were a paired-associate learning task, the Betts vividness of imagery questionnaire, and the Gordon test of imagery control. 
A second study was conducted in conjunction with the current research project (Edney, 1980). The second study, hereafter referred to as Study II, was designed to compare three techniques of assessing waking fantasy. The methodology presented here includes a description of a11 Study II procedures, since the same subjects served in both studies. The measures used in Study II included a Thematic Apperception Test (TAT), the Imaginal Processes Inventory (IPI), and time-sampled ongoing mentation reports (OMR). Study I and Study II shared certain data from the OMR and the IPI. 


\section{SEVERAL RELATED THEORIES OF CONSCIOUSNESS}

Beneath man's thin veneer of consciousness lies a relatively uncharted realm of mental activity, the nature and function of which have been neither sytematically explored nor adequately conceptualized. (Ludwig, 1972, p. 11)

According to Tomkins (1962), the most essential characteristic of a living system is its ability to duplicate itself in time and space. Through the process of energy and information transformations, consciousness has evolved as a unique type of duplication by which some aspects of the word reveal themselves to another part of the same world. Yet, the afferent sensory data are not directly transformed into a conscious report. What is consciously perceived is imagery which is created by the organism itself, a process referred to as a "feedback matching mechanism under central control" (Tomkins, 1962, p. 13).

Ornstein (1972) also discusses the construction of consciousness in terms of a duplicating process. He proposes, on the basis of evidence from habituation studies, that we tune out the recurrences of the world by making a model of the external world from selected input within our nervous system. We then test new input against this model, all of the time programming, and continuously reprogramming or revising, our models of the external world. In this way we achieve some stability of awareness out of the complex and continuously changing flow of information reaching our receptors. 
The necessity of such a process is due partially to the fact that, as a receiver of data, an individual is being assailed with an overabundance of sensory stimulation which renders him/her vulnerable to confusion and to data overload. Thus, the individual must somehow select data to emphasize one sensory channel over another and focus on limited aspects of the incoming data within that channel. Matching this constantly changing sensory input is a skill that one learns as any skill; a skill which eventually supports subsystems in which central stimulation produces conscious imagery in the absence of afferent input (Tomkins, 1962). Klinger (1971) discusses subsystems as processes which encompass certain affective tones, associated memories, dispositions, and attitudes most central to oneself, of which the imaginal aspect of fantasy is a part.

Pylyshyn (1973) refers to cognitive representation as the form in which our knowledge of the world is represented as a model in the mind. Many psychologists assume that the only forms of mental representation are words and images, but Pylyshyn points out that these do not exhaust the available forms of mental representations. They are, however, the primary way we experience the underlying process of our cognitive representations in consciousness.

Neisser (1972) conceptualizes mind as the totality of ways that people process information. These processes result in representations of the environment, available to consciousness, which have been constructed on the basis of specified data. It is this construction, or reconstruction, of internal representations of the environment in the absence of external stimuli, that is referred to as imagery. Imaging 
is a constructive process in the sense that while it depends on information stored earlier, it does not simply revive that information. Rather, the individual is carrying out a new activity, perhaps forming new representations more or less consistent with the original perception. These processes may at times involve forming representations of an entire environment, while at other times they may be more fragmentary. In either case, they are complex and multi-layered, so that a person's introspections may take many different forms and will be easily influenced by extraneous factors. Neisser (1972) concludes that "if we consider the differences between individuals, it becomes increasingly obvious that we would be wrong to consider imagery a unitary phenomenon" (p. 244).

Sperling (cited in Pylyshyn, 1973) states "that in any system which examines itself there must ultimately be some part of the mechanism which is inaccessible to examination from within" (p. 292). Personal consciousness is thus seen as an ongoing internal process, aspects of which we are able to observe through various modes of awareness, yet the essence of which remains below our awareness. Evidence for such a view comes from the work of Starker $(1973$; 1974) who has found that certain qualitative dimensions of mental functioning are consistent in dreams, daydreams, and other mental productions of an individual.

In this brief review of several related theories of consciousness, imagery is seen as a process of cognitive representation which occurs during the development of consciousness, which in turn serves to sustain that consciousness. The next chapter will further explore 
consciousness in terms of two different, yet complementary, modes of conscious experience. 


\section{CHAPTER III}

\section{TWO MODES OF CONSCIOUSNESS}

\section{THEORETICAL MODELS}

There is a growing body of research which demonstrates that man has two major modes of consciousness. Each paragraph below will present a particular researcher's theory concerning man's two modes of conscious experience. Although different terminology is employed by each of the researchers, the underlying distinction between the two modes concerns verbal and imaginal/spatial cognitive processes.

Deikman (1971) describes these modes in terms of a receptive mode, oriented toward maximizing the intake of the environment, and an action mode, oriented toward the manipulation of the environment. Language is the essence of the action mode, through which we can discriminate, analyze, and divide the world into objects which can then be acted upon. Thus we manipulate our environment through language-mediated strategies. However, the Whorfian hypothesis--that we are unable to think outside our language structues--has relevance only for the action mode, suggesting that the receptive mode processes information non-verbally. This bi-modal model presents different strategies for experiencing the world, depending upon the extent of dominance of a particular mode. Deikman (1971) concludes that the characteristic way an individual attends to stimuli, his/her attentive style, has important effects influencing the individual's conscious experience. For instance, it is 
proposed that the action mode is characterized by focal attention and object-based logic, whereas the receptive mode is characterized by diffuse attention and paralogical thought processes.

Richardson (1969) devised a typology contrasting habitual visualizers and habitual verbalizers. The habitual visualizer experiences fairly concrete vivid imagery. Such individuals may on occasion resort to inner speech and engage in problem solving without being aware of accompanying imagery. However, visual imagery is a frequent and spontaneous accompaniment to much of their thinking and to most of their daydreaming. Visual images arise easily and may be utilized deliberately as a method of concretely representing some past, present, or future event. Habitual verbalizers, on the other hand, experience weak or vague concrete imagery with little or no visual imagery. The verbalizer may express memory images, but visual imagery does not play a significant role in cognitive functioning. Problem solving is an imageless process, though usually accompanied by inner speech. "There may be a predominance of kinaesthetic imagery from the larynx and tongue, and some verbal and auditory imagery" (Richardson, 1969, p. 62). The visual and verbal modes of encoding, storing, and decoding information are alternative strategies, though not mutually exclusive for most people. However, preferred strategies develop in different individuals and in extreme cases these become habitual with little switching from one strategy to another.

Ornstein (1972) states that one of the most basic differences between individuals is between those who tend to employ the linear, verbal mode and those who are less verbal, and more involved in spatial imagery. 
He goes further in delineating these two modes by suggesting that differences between right and left hemispheric functioning may be the basis to our understanding of the psychological and physiological mechanisms of the two major modes of consciousness. Both the structure and the function of the two cerebral hemispheres to some extent underlie the two modes of consciousness which coexist within each of us. The left hemisphere is specialized for verbal and math functions, with an analytical and logical orientation. Its mode of operation is primarily linear, processing information in a sequential manner. The right hemisphere is specialized for holistic mentation with a spatial orientation. Its mode of operation is primarily simultaneous, processing information in a relational manner. In most ordinary activities, we simply alternate between the two hemispheres, selecting the one appropriate for the task and inhibiting the other. However, some persons habitually prefer one mode over the other.

Bower (1970) views the verbal and visual modes as different processing systems and suggests, as in the previous discussion, that the systems might be functionally discriminated along hemispheric distinctions. A verbal processing system, which is specialized for speech and abstract information, may be primarily a left hemisphere function, while a visual processing system, which is more adept with spatial and concrete information, might be predominantly associated with the right hemisphere.

These theories have been speculative in nature thus far. The next section will concentrate on empirical evidence which supports the theories just reviewed. 


\section{EMPIRICAL EVIDENCE}

Neurophysiological research has contributed to this differentiation of a two processes theory by demonstrating that the mechanisms subserving verbal and non-verbal processes are, to a considerable degree, distinct anatomically as well as functionally. The first set of evidence comes from research with lobectomy patients (Kimura, 1973; Milner, 1968). These investigations have shown that left hemisphere lesions are associated with behavioral deficits that can be conceptualized as a loss in verbal symbolic abilities, whereas right hemisphere lesions produce selected deficits in the individual's ability to process non-verbal information.

Another source of evidence comes from cerebral commissurotomy investigations (Bogen, 1969; Gazzaniga \& Sperry, 1967; Nebes, 1974, 1978; Sperry, 1973). Since the two cerebral hemispheres were in essence dissociated, the researchers were able to isolate and confine visual information to one or the other hemisphere. In this manner, the two hemispheres were found to be neurophysiologically specialized to process information in two different complementary modes. The left hemisphere processes information in a linear, sequential manner appropriate to its specialities of verbal representation and rational thought. The right hemisphere processes input more as a patterned whole in a simultaneous manner, according to its specialized non-verbal or visual representation.

A recent discovery involving hemispheric functioning is that lateral eye movement (LEM) can be a reliable indication of a predominance of activity in the cortical hemisphere contralateral to the direction of 
the eye movement (Bakan, 1971; Day, 1967; Harnard, 1972; Kinsbourne, 1972; Kocel et a1., 1972; Meskin \& Singer, 1974). Furthermore, the direction of LEMs to left or right is relatively consistent for an individual, so that one can be classified as either a left or right mover on the basis of predominant direction of eye movement. Bakan (1971) states that on the average, people make about $75 \%$ of their LEMs in one direction, either left or right, though women are less consistent in the direction of LEMs than men.

It has also been found that consistent eye movement patterns are associated with certain personality traits and cognitive styles (Bakan, 1971; Day, 1967; Meskin \& Singer, 1974). The cognitive style of a left mover is more likely to reflect the style of right hemisphere functioning, and consequently, the cognitive style of a right mover is a reflection of left hemisphere functioning. Thus, left movers (right hemisphere activators) show greater use of images and more vivid imagery, an internal focus on subjective experiences, are more fantasy-oriented, more susceptible to hypnosis, have more humanistic interests with college majors in classical, humanistic areas, show more spatial ability, and more emotionality. Right movers (left hemisphere activators) are more verbal, externally oriented to objective experience, analytical, rational, and are more likely to major in science and quantitative areas.

Day (1967) states that this phenomenon of different cognitive styles for left movers and right movers suggests a theoretical view of how selective attentional processes may be organized. He proposes a dualistic model of attentional processes. Right movers show an 
externalized, objective, actively responsive distribution of attention, whereas left movers exemplify an internalized, subjective, passively expressive distribution of attention. Recent evidence suggests that the two hemispheres do function at different levels of arousal, with the left hemisphere functioning at a higher level of arousal than the right hemisphere (Bakan, 1971). Also, EEG alpha waves, associated with a low arousal state, are found in greater quantity over the right hemisphere. Certain states of consciousness, such as daydreaming and hypnosis, are also associated with relaxation and low arousal and might be associated to a greater extent with right hemispheric functioning (Harnard, 1972).

The implication of these interrelationships is that a person who makes more left LEMs, experiences more vivid imagery, has an internal focus of attention on subjective experience, is more susceptible to hypnosis, etc., is this way because his/her right hemisphere is relatively more dominant in his/her total psychological functioning. In the case of a right mover, this would implicate the left hemisphere as a more dominant force in the individual's psychological functioning. Such stylistic differences are considered a reflection of differential habitual activation of the left hemisphere (for right movers) associated with localization of verbal capacities, and the right hemisphere (for left movers) associated with non-verbal, visual imagery and spatial capacities. The concept of two organizational modes is thus based on the idea that psychological and physiological activities are integrated in the service of the total organism, and the functional attitude of the organism is the crucial determinant of which mode is adopted (Deikman, 1971). 


\section{IMAGERY AND VERBAL PROCESSES}

\section{FUNCTIONAL DISTINCTIONS}

Restricting the discussion to imagery and verbal processes does not imply that these are the only modes of representation in consciousness. Rather, they are the most obvious modes and are most commonly represented in the literature. Imagery and verbal processes are distinguished primarily in terms of their functions as symbolic systems (Paivio, 1971, 1971b). Imagery involves non-verbal mental representations or modes of thought. Unless otherwise specified, the term imagery will be used in this context to denote non-verbal visual imagery. The verbal symbolic mode of thought is a process assumed to involve implicit activity in an auditory-motor speech system.

Alan Paivio, one of the leading researchers in the area of imaginal and verbal symbolic processes, views the two processing systems as functionally independent but partly interconnected cognitive systems for encoding, storing, organizing, transforming, and retrieving stimulus information (Paivio, 1971, 1971b). The term independence refers to independent storage and independent processing within the two systems. Information can be stored and processed in either the imaginal or the verbal system, or in both simultaneously. Neurophysiological evidence for functional independence was cited previously. Further evidence to support the idea that visual and verbal information are dealt with in 
distinct, modality-specific manners comes from the research on interference in same-modality tasks (Brooks, 1968; Paivio, 1975; Segal \& Fusella, 1969). It was found, for instance, that memory (e.g., mnemonic) activity can go on in the imagery channel, while the verbal channel is concurrently engaged in perceptual activity (e.g., listening), but the same channel cannot efficiently carry on both perceptual and memory processing (Paivio, 1975). The conclusion drawn from these studies was that imagery mediation is indeed a process that involves the visual system, whereas abstract verbal mediation implicates the auditory system. The two systems become interconnected, however, through associative experience involving language and concrete objects and events (Paivio, 1971b, 1973). Very simply, words can be transformed into images, non-verbal stimuli can be labeled, and transformations can occur cognitively from images to implicit speech and vice versa.

The two processing systems are also assumed to differ functionally in regard to the nature of the information they are specialized to handle, the way that information is organized into higher-order structures, and the ease with which the cognitive information can be recognized or transformed (Paivio, 1975).

Thus the imagery system is assumed to be specialized for relatively direct processing of information concerning concrete objects and events; it organizes elementary units of information (images) into higher-order structures that have a synchronous or spatial character; and it is functionally dynamic and flexible in that the organized cognitive information can be quickly reorganized, manipulated, or transformed. The verbal system is specialized for dealing with abstract information involving linguistic units and organizing such information into higher-order sequential structures. (Paivio, 1975, p. 59).

The verbal system is not as flexible as the imagery system due to grammatical, logical, and sequential constraints (Richardson, 1969). 
A factor analytic study conducted by Paivio and Rogers sought to determine the relations among individual differences in imaginal and verbal processes (Paivio, 1971b). The degree to which subjects habitually used verbal and imaginal modes of thought was assessed by an 86item true-false questionnaire. Items were selected on an intuitive basis with the assumption that individuals vary in their typical cognitive approaches to different tasks. In this way symbolic habits as well as abilities were measured.

The most encouraging implication of the factor structure is that imaginal and verbal processes emerged as different cognitive dimensions, just as they had in Thurstone's original work and in Guilford's recent research on the structure of the intellect. (Paivio, 1971b, p. 495)

Thus it appears that imagery and verbal processes can be differentiated not only in theory but empirically as well. The following section discusses the two modes in terms of operational distinctions.

\section{EMPIRICAL APPROACH}

Theoretical distinctions are only useful to the extent that verbal and imaginal processes can be operationally distinguished. In most of his investigations, Paivio has employed one form or another of a pairedassociate learning task in order to operationally distinguish the different variables involved in imagery and verbal processes (Paivio, 1965, 1967, 1968, 1969; Paivio \& Csapo, 1969; Paivio \& Foth, 1970; Paivio \& Madigan, 1968; Paivio \& Yuille, 1969; Yuille \& Paivio, 1968). In this way imagery and verbal processes serve a mediationary role for new data to be encoded. The most common general interpretation of mediator effectiveness is in terms of transfer: the use of mediators essentially 
involves the application of information in long-term memory storage to the learning of new response units or new associations (Paivio, 1971b). Thus, when an individual uses mediators, he/she is taking advantage of the pre-established representations or associative habits to construct a more meaningful, and therefore more available, relationship between units.

The empirical approach to a PAL task involves three major classes of independent variables. One is concerned with stimulus attributes, defined along an abstract-concrete dimension. Thus, the noun-pairs used in the paired-associate task vary in their image-evoking capacity, as measured by subject's ratings or reaction time data. Another variable is experimental manipulation, which involves mnemonic instruction, presentation rate, and task demands, and is designed to increase or decrease the probability that imagery or verbal processes will be effectively used. Individual differences in imaginal and verbal habits and abilities defines the third variable, and is the most important for the purpose of the present study. All of the variables are designed to affect the availability of one or the other symbolic processing system in a given task.

Paivio (1971, 1971b) concludes from evidence of recent investigations that both verbal and imaginal mediators greatly enhance learning as compared to appropriate control conditions, but that they are sometimes differentially effective. The differential effects of the two classes of mediators can be analyzed in terms of concrete-abstract, parallel-sequential, and dynamic-static functional dimensions between the two systems. 
On the concrete-abstract dimension, imagery mediation interacts with item concreteness in such a way as to enhance imaginal association to concrete stimuli more than to abstract stimuli. Consequently, there is a facilitating effect on learning when the items are concrete but not when they are abstract. The inferiority of imagery with abstract noun-pairs is due to the difficulty in generating images for such pairs. This is evidenced by significantly longer latencies for imagery than for verbal mediators, as well as relatively more failures to produce images, in the case of abstract noun-pairs. As such, images are much less available for abstract than for concrete noun-pairs. No such interaction occurs in the case of verbal mediators, in that they are equally available for concrete or abstract nouns. The research shows that imagery mediators produce better recall than verbal mediators with concrete noun-pairs, whereas verbal mediators are generally more effective with abstract noun-pairs. However, there are exceptions to this general finding in that some individuals can use imagery effectively with abstract pairs, which would suggest that imagery processes in general might be more available for these people (Paivio, 1971b).

The distinction between spatially parallel and sequential processing of information in imaginal and verbal symbolic systems implies that imagery should be advantageous in memory tasks that involve spatial organization of informational units or retrieval of spatial information from memory, whereas verbal processes should be superior in tasks that require the sequential order of items to be remembered. This functional distinction may provide a partial explanation for the apparent superiority of imagery with concrete items. With integrated images, information 
is associated and stored in parallel form. The image can be quickly scanned and decoded to yield a verbal response. Verbal mediators associate and store information sequentially, which could result in a greater memory load and a longer decoding process (Paivio, 1971b). Neisser (1967) postulates that parallel processing of multi-faceted information proceeds more quickly than sequential processing of the same amount of information.

Paivio (1971b) suggests that images are particularly effective in promoting rapid and flexible associations while verbal processes give them direction and organization. This distinction might shed some light on the fact that even though images are in some respects superior to verbal mediation, they are also particularly susceptible to decoding errors under some conditions (Paivio, 1975; Yuille, 1973). It also has implications for the finding that imagery ability is especially relevant in incidental learning. High imagers were found to be superior to low imagers in their incidental recall of the irrelevant component of a compound stimulus (Bower, 1972; Earnest \& Paivio, 1969). Imagery is assumed to encode visual information literally, to some extent, whereas verbal processes are more likely to encode information according to some classification schema. Thus, incidental cues are unlikely to be coded into the verbal schemata, whereas such. cues would be more readily available to imagery processing (Paivio, 1971b; Sheehan, 1966). In this respect, imagery is characteristic of autistic thinking in general and in that context is free of logical or sequential constraints. Verbal processes, superimposed on such imagery, presumably contribute order and direction. 
It would appear, then, that we would be more efficient problem solvers if we could utilize both forms of representation, both within a problem and between types of problems. In an early experiment involving "professional problem solvers," it was found that their thinking showed constant alternations between abstract numerical and verbal modes of thought on the one hand, and concrete imaging on the other (Hyman \& Anderson, 1956). The advantage of such alternatism is that it provides a basis for breaking an unproductive set toward the solution to a problem. Short (1953) also hypothesized that the "mixed" type of representation has advantage when moving from the solution of a problem where verbalization is more appropriate to the point where an ability to visualize is especially useful. However, using a stereognosis task, Short and Walters (1954) found that better performances were achieved by habitual verbalizers and habitual visualizers than by those who switched between the two modes. Thus is appears that the value of an ability to switch modes needs to be further investigated.

The discussion which follows concerns the practical problem of discovering criteria and employing reliable measurements to distinguish subjects as imagers or verbalizers, who would in turn perform differentially on a variety of tasks. Most researchers have relied on a variety of tests involving spatial or verbal ability, or self-report measures of such abilities. However, these attempts have generally yielded inconsistent results. In the present study, an individual's habitual symbolic mode was measured by an ongoing mentation report. Both timesampled ongoing mentation reports and EEG-EOG recordings of hemisphere activation were utilized. In this way, a comaprison was made between 
the classification of "imager" or "verbalizer" and corresponding activation of left or right hemisphere. It was expected that those classified as verbalizers on the basis of ongoing mentation would also prove to be left hemisphere activators on the EEG-EOG measure. Those classified as imagers would be expected to show a preference for right hemisphere activation. Thus, the measure should provide a firm basis for establishing a person's habitual symbolic mode.

A paired-associate task was used as a performance measure of the subject's ability to use imaginal or verbal processes. Paivio (1971, 1971b) states that research is needed which incorporates relevant item attributes, instructional sets, and individual differences in a single design. The PAL task, as discussed in the procedure section, met these requirements.

Paivio (1971b) found that associative strategies are only partly controlled by experimental sets and that, over trials, subjects increasingly revert to associative habits aroused by the semantic attributes of the task items. Due to this difficulty of establishing persistent sets to use mediating devices that are incongruent with the associative process most readily aroused by the nouns themselves, the PAL task involved concrete nouns with imagery mediation, and abstract nouns with verbal mediation. It was assumed that imagers would perform somewhat better on concrete-imagery tasks and that verbalizers would do better with the abstract-verbal tasks. Furthermore, on the trials which do not specify a mnemonic strategy, it was expected that some subjects would show a preference for either imagery or verbal mediation, depending on their habitual symbolic mode. It was also expected that some 
individuals would not be classified in an either-or distinction, but would form a mixed group. Such individuals would be expected to show a greater ability to switch back and forth in their symbolic modes, according to task demands.

A third area of measurement was in the form of self-report questionnaires. The results in the literature have been inconsistent in relating self-report measures of imagery with performance measures of imagery. It would be expected that subjects who report more vivid imagery would make more effective use of it in a memory task than those who report poor imagery. Yet, Neisser (cited in Paivio, 1971b) makes a distinction between imagery as a process that represents spatial information effectively and imagery as a subjectively reported experience whose vividness may be unrelated to its usefulness or accuracy. In fact, imagery, if uncontrolled, might be a hindrance rather than a help (Richardson, 1972). Thus Doob (1972) suggests that an interaction of vividness and controllability might provide a more useful measure of the adaptive utility of imagery. Richardson (1969) suggests, in the context of studies using the Betts vividness questionnaire and Gordon's test of controllability, that the two variables may interact to produce predictable differences in performance. Results of those studies showed some success in the prediction of such behavior as image mediated motor learning. In the present research design, the Gordon test and Betts questionnaire were employed and results compared with the measures of symbolic habit and ability to see what, if any, correlations exist. 
CHAPTER $V$

\section{DESCRIPTION OF THE PRESENT STUDY}

\section{STATEMENT OF PURPOSE}

The purpose of the present study was to distinguish "imagers" from "verbalizers" who would in turn perform differentially on other measures. The ongoing mentation report provided a basis for classifying subjects according to their preferred symbolic mode. The OMR reports were coded for vividness of imagery by independent judges who rated each mentation report on a scale from 0 (no content reported) to 3 (hallucinatory percentual content) (see Appendix A). The criterion for classifying subjects as verbalizers or imagers depended on at least $60 \%$ of the mentation reports being coded as either conceptual or perceptual. Also, the EEG/EOG record was marked during the $O M R$ so as to indicate each time-sampled interruption. Thus, eye movements during the 15-second interval preceding the mentation report were recorded for each subject. The criterion for classifying subjects as left movers or right movers was defined by requiring at least $60 \%$ of a subject's LEMs to be made in one direction, either left or right. Meskin and Singer (1974) were able to classify 42 of 48 subjects as left or right movers on the basis of $60 \%$ of their eye movements being made in one direction during a questionnaire interview. The subjects who did not meet this criterion were placed in a "mixed" mover group. It was predicted that verbalizers would show a predominance of right LEMs, thus implicating the left 
hemisphere. Consequently, imagers were expected to show a predominance of left LEMs, indicating right hemisphere activation.

The PAL task was a measure of the number of concrete and abstract nouns recalled by each subject. It was assumed that the difference between recall test performance in trials II and III would be a function of individual differences (i.e., whether subjects were imagers or verbalizers). It was predicted that overall performance on trial II (concrete/imagery) would be superior to the results on trial III (abstract/verbal), but that imagers would perform better than verbalizers on this task. It was expected that verbalizers would perform better than imagers on trial III. Thus, trials II and III measured a subject's ability to use imagery and verbal mediation on the basis of number of nouns recalled.

The purpose in using the Betts questionnaire, Gordon's test, and IPI visual imagery scale, was to see what, if any, correlations exist between self-report measures of imagery vividness/controllability and the previous measures of imagery and verbal habits and abilities. It would be expected that those subjects who rate high on self-report imagery scales would also rate high on spontaneous vivid imagery as coded by the OMR.

METHOD

\section{Subjects}

Twenty-five subjects were recruited from undergraduate psychology courses at Portland State University. A subject's participation was related to his/her grade in a course only to the extent that extra 
credit was offered by some instructors. Each subject was paid $\$ 5.00$ upon completion of all measures. Due to equipment failure and subject recidivism, the final $\mathrm{N}$ for this study was 16: 4 males and 12 females.

An initial interview was employed to screen for psychiatric disturbance, as well as to gather biographical data. Due to the recommendation for use of the Imaginal Processes Inventory, only native Englishspeaking subjects were used. Also, left-handedness was screened out due to mixed hemisphere organization (Corballes \& Beale, 1976).

The age range of the sample was 19 to 37 years, mean age was 25 , mode was 23, standard deviation was 5.28. All of the subjects were Caucasian. Fifteen of the subjects were full-time summer students. One subject was not enrolled in classes for the summer, but was working as a research assistant in the Department of Psychology. Seven subjects stated an academic major in Psychology, two in Education, two in Business, two in General Studies, and one each in Nursing, Biology, and Social Work.

Eleven of the subjects stated an occupation. Five had part-time clerical/office jobs, one was an unemployed secretary/tutor, one a full-time machinist, two manual laborers (one employed part-time, one unemployed), one part-time musician/promoter, and one part-time salesperson. The remaining subjects did not report an occupation and were not working at the time of the study.

\section{Procedures}

The tasks were divided into two sessions, each of which took about two hours for the subject to complete. The first session was conducted with each subject individually; the second session was conducted with 
groups of subjects. The time of day that the sessions were scheduled depended on the availability of the subject.

Session One. This session consisted of the OMR, the PAL, and the Betts and Gordon questionnaires.

The procedures used for the OMR approximated as closely as possible (based on the published article) those procedures employed by Foulkes and Fleisher (1975). The sessions were conducted at various times during the day between the hours of 9:00 A.M. and 8:00 P.M. Two OMRs occurred at 9:00 A.M., six at noon, six at 3:00 P.M., and two at 6:00 P.M.

The room was moderately illuminated by two table lamps (150 and 75 watts), each located approximately six feet from the subject. No attempt was made to eliminate incidental sounds from the hallway, although most subjects commented on the noise made by the ventilation system of the building. The noise was one of rushing air, and resembled white noise. Every attempt was made to provide a setting which was similar to one encountered in everyday situations of relaxation.

Subjects were oriented to the task as a daytime practice session for the establishment of waking baseline responses to a structured interview designed for use in sleep research. The nature of sleep research was described to the subject (i.e., monitoring of sleep, awakenings, and use of the interview questions). It was pointed out to the subject that the questions may not apply too well to waking experiences. See Appendix B for the script used for this orientation.

Electrode placements for EEG and EOG monitoring were then made. Frontal placements were used for the EEG, and EOG placements were made 
according to the criteria outlined in Rechtschaffen and Kales (1968). The subject was shown a copy of the questionnaire to be used in reporting mentation. See Appendix $C$ for a list of these questions. The experimenter reviewed each question with the subject to ensure understanding. During this time, a second experimenter calibrated the physiograph in the next room.

The subject was then asked to lie down and relax but to stay awake. It was suggested that the subject might want to close his eyes to promote relaxation, but that this was not a requirement. The experimenter than left the room and allowed a five-minute adaptation period before beginning the timed interruptions. Subjects remained in this relaxed state for 45 to 60 minutes, during which time the experimenter, isolated in the next room, interrupted the subject at six randomly selected times. The interruptions ranged from one to nine minutes after the end of the previous interview (adaptation period or mentation report). The experimenter called the subject's name over a speaker system, and went through the questions contained in Appendix C.

The subject's answers were recorded on magnetic tape, transcribed on individual scoring sheets, randomly ordered, and given to two judges to rate for the content areas under study.

In order to make comparisons with previous research, Regressivity and Reality Contact were scored for OMR. In order to make comparisons with other measures used in this study, the reports were rated for emotional tone, outcome, achievement, aggression, sex, bizarreness, and vividness. For the purpose of the present study, the vividness scale was utilized to analyze each subject's report as to a predominance of 
visual or verbal mentation, thus leading to a preliminary classification of subjects as "imagers" or. "verbalizers." Vividness of imagery was assessed by a modification of the Dreamlike Fantasy scale (Foulkes, 1971; Foulkes, Spear, and Symonds, 1966). This scale consists of rating the report from 0 (no content reported, feels mind was blank) to 7 (perceptual content which is hallucinatory). The modified scale, which removes any mention of the bizarreness of the image, ranges in value from 0 to 3, using the same end-points as the full scale. The modified scale is presented in Appendix $A$.

A four-channel physiograph (E \& M Instruments, Model 4-A) was used to monitor EEG and EOG for the entire relaxation period. The paper speed was $1.0 \mathrm{~cm} / \mathrm{sec}$, the minimum speed recommended by Rechtschaffen and Kales (1968) for reliable recording of EOG and EEG. Selective filtering was set at $30 \mathrm{~Hz}$, except during periods of interference (60-cycle fluctuations, subject muscle tension, etc.) at which times the filter was set at $10 \mathrm{~Hz}$. Pen deflection ranged from $200 \mathrm{mV} / \mathrm{cm}$ when the filter was set on $30 \mathrm{~Hz}$, to $50 \mathrm{mV} / \mathrm{cm}$ when the filter was set at $10 \mathrm{~Hz}$.

The physiograph record was used to determine lateral eye movements for each subject. This record was then used in classifying subjects as having a preference for left or right hemisphere activation. The EEG and EOG measures also provided a basis for judging whether or not the subject was awake or asleep at the time of the mentation report. Slow, rolling eye movement was the primary indicator of sleep onset. Additionally, a report from the subject that he/she was "drowsy," "drifting off," or in "light sleep" (question 10) was used as a criterion. When both the physiological and subjective assessment coincided in indicating 
sleep onset, the report obtained was discarded. Thus, the interruptions scored and reported were obtained from waking subjects.

The paired-associate learning task ( $P A L$ ) used a revision of the procedure employed by Yuille and Paivio (1968). All subjects were presented a standard set of procedural instructions which specified that the experiment was concerned with learning noun-pairs (see Appendix D). Each noun-pair was presented manually by the experimenter at a constant rate of 6 seconds per card. Each subject participated in four separate paired-associate learning trials, each trial consisting of a list of 10 noun-pairs. During this time, the subject was continuously monitored by $E E G$ and $E O G$ recordings.

The conditions for trial I excluded prior mnemonic instructions and were identical for a 11 subjects. Each subject was presented the first list of noun-pairs. This list consisted of five concrete and five abstract noun-pairs presented in random order. This was followed by a recall test, with the experimenter presenting the stimulus noun and the subject recalling and writing the response noun. The subject then filled out a brief questionnaire describing how he/she remembered the noun-pairs. Tiral I yielded a baseline measure of PAL performance for a11 subjects.

The conditions for trials II and III included two different mnemonic instructions (imagery and verbal) and two corresponding PA lists (concrete and abstract, respectively). The order of sequence for trials II and III was counterbalanced so that half the subjects were randomly selected to receive trial II first and trial III second. The remaining half received trial III first and trial II second. 
For trial II, each subject was told that he/she was going to learn a mnemonic technique which would help him/her to remember word lists. The subject then listened to a set of standardized imagery instructions describing how to combine each noun-pair by forming a mental image, or picture, of the appropriate objects together (see Appendix D). Each subject then practiced the technique with two noun-pairs, drawing the mental image on paper so that the subject's understanding of the imagery instructions could be verified. It was emphasized that the quality of the drawing was unimportant. The subject was then presented with a list of 10 concrete noun-pairs, followed by a recall test as in trial I. This was followed by the questionnaire.

The procedure for trial III was the same as in trial II, the difference being that an abstract word list was employed and the subjects were instructed to use a verbal mnemonic strategy. Each subject was instructed to construct a sentence or phrase for each noun-pair in which the nouns were embedded and associated in some manner (see Appendix D). On the two practice noun-pairs, the subject was asked to write the mediating phrase on paper, again to insure the subject's understanding of the technique. The questionaire followed the recall test, as in trials I and II.

The conditions of trial IV repeated those of trial I. The subject received no mnemonic instruction and was told to perform the task in the easiest manner. The PA list, as in trial I, consisted of five concrete and five abstract noun-pairs presented in random order, followed by a recall test and questionnaire. 
The nouns in the four paired-associate lists ( 10 word pairs each) were selected from a list of 925 nouns with norms for concreteness (C), imagery (I), and meaningfulness (Paivio, Yuille, and Madrigan, 1968). See Appendix E for PA lists. The concrete list consisted of 20 randomly paired nouns rated high on $C$ and I (means approximately matched across words). The abstract list consisted of 20 randomly paired nouns rated low on C. and I (means approximately matched). The frequency of usage for all nouns was approximately matched across lists (Thorndike \& Lorge, 1944). Each word pair was typed in upper case letters on an unined 3" $\times 5^{\prime \prime}$ card.

The self-report, post-trial questionnaire consisted of two parts (see Appendix F). The first part consisted of two questions with corresponding 7-point scales. The scale for question 1 (how easy or difficult the subject found the instructed mnemonic strategy) was defined by 1 (very easy) to 7 (very difficult). The scale for question 2 (how often the subject used the instructed technique) was defined by 1 (none of the pairs) to 7 (all of the pairs). The second part contained a list of the noun-pairs employed in the preceding trial, along with instructions for the subject to draw (trial II) or write (trial III) the mnemonic mediation actually used to remember each noun-pair.

The Betts and Gordon questionnaires were administered after completion of the PAL. The Betts is a subjective measure of vividness of imagery. Sheehan's shortened version of the Betts was used, as it appears in Richardson (1969). It contains seven subscales which require the subject to rate the clarity and vividness of specific images across the different sense modalities: visual, auditory, tactile, kinesthetic, 
taste, sme1l, and bodily sensations. All subtests use a rating scale from 1 to 7 , with a rating of 1 representing images which are "perfectly clear and as vivid as the actual experience" and a rating of 7 representing "no image present at all, you only know that you are thinking of the object."

The Gordon test of imagery controllability, as revised by Richardson (1972) and adapted for this study, followed the Betts questionnaire (see Appendix $H$ ). The subject was instructed to visualize a specific image in each of the sense modalities listed above, and was then asked to change the image in a specific way. The subject was then asked to rate his/her ability to visualize the requested scene by indicating a rating of yes or no. The instructions emphasize ability to control and change imagery, rather than the vividness of the imagery. The Gordon test and Betts questionnaire were administered on an individual basis as advised by Richardson (1972).

Session Two. This session consisted of group administration of the Thematic Apperception Test and the Imaginal Processes Inventory, as well as debriefing of subjects and payment for their services.

The subjects were asked to respond to six TAT cards (4, 7BM, 10, 13MF, 14, and 20) in a session conducted by the experimenter. The cards were selected to yield a variety, of themes, according to the normative data reported by Eron (1950). The cards were also selected as moderately ambiguous, according to the list provided by Bijou and Kenney (1951).

The cards were projected on a screen with an overhead projector, each card being projected for one minute. The subjects were given five 
minutes to write their responses. The stories thus obtained were coded by two independent judges for the same categories, using the same criteria as the OMR. Regressivity and reality contact were not scored for TAT stories. The latter two measures are scored only for the purpose of comparing the results of Study II with the findings of Foulkes and Fleisher (1975).

When instructing the subjects, the experimenter made no reference to the purpose of the test. The subjects were asked to write three aspects of the story: (1) what is going on in the scene? (2) what led up to the scene? and (3) what will happen after the scene, or what will the outcome be?

Upon completion of the TAT, each subject was asked to complete the IPI. The IPI is a 344-item test to which the subject responds on a 5-point Likert scale. It assesses 28 aspects of daydreaming. A list of the 28 subscales is located in Appendix I. In the present study, only the visual imagery scale was used. 
CHAPTER VI

\section{RESULTS}

The criterion for significance of results will be set at the .05 level for two-tailed tests unless otherwise specified. The first hypothesis postulated that verbalizers would show a predominance of right LEMs and imagers a predominance of left LEMS. In a chi ${ }^{2}$ comparison of the eye movement classification with the imager/verbalizer classification, the prediction was not supported $\left(c h i^{2}=5.827, \mathrm{df}=4\right.$ ) (see Table I).

TABLE I

SUBJECT-BY-SUBJECT ANALYSIS OF CLASSIFICATION BY EYE MOVEMENT AS COMPARED WITH CLASSIFICATION BY TYPE OF REPORT

\begin{tabular}{l|c|c|c|c}
\multicolumn{1}{c|}{ Type of Report } & Left & Right & Mixed & Row Total \\
\cline { 2 - 5 } & 5 & 1 & 3 & 9 \\
Imager & 4 & 2 & 0 & 6 \\
Merbalizer & 0 & 0 & 1 & 1 \\
& 9 & 3 & 4 & 16 \\
\hline
\end{tabular}

$\mathrm{Chi}^{2}$ was also calculated for the individual OMR reports based on perceptual/conceptual ratings, and eye movement direction, which was used as a basis for the previously mentioned classifications. Again there was no significant relationship between type of report and 
direction of eye movements $\left(c h i^{2}=1.42, d f=1\right)$. See Table II for this comparison. In analyzing percentages of LEM direction (60\% left or right) to type of report, it was found that LEMs corresponding to perceptual reports are $66 \%$ to the left, which is in the predicted direction. It is important to note, however, that $72 \%$ of all eye movements were to the left (see Table II). Thus, the majority of all LEMs, regardless of type of report, were to the left. Also, $60 \%$ of all eye movements regardless of direction, coincided with perceptual reports. Thus, LEMs in general were found to be associated with perceptual reports.

\section{TABLE II}

REPORT-BY-REPORT COMPARISON OF EYE MOVEMENTS BY TYPE OF REPORT

\begin{tabular}{c|c|c|c}
\hline \multirow{2}{*}{ Type of Report } & \multicolumn{2}{c}{ Eye Movement } & \multicolumn{1}{c}{ Row Total } \\
\cline { 2 - 4 } Perceptual & $27 / 40 \%$ & $>60 \%$ Right & $41 / 60 \%$ \\
Conceptual & $\frac{22 / 32 \%}{48 / 72 \%}$ & $\frac{5 / 07 \%}{19 / 28 \%}$ & $\frac{27 / 40 \%}{68}$ \\
\hline
\end{tabular}

The second hypothesis concerned recall of concrete and abstract nouns on trials II and III, respectively, of the PAL task. Three predictions were made in relation to this hypothesis. The first assumption tested was that overall performance on trial II would be superior to trial III performance for both verbalizers and imagers. To compare trials II and III within groups, an ANOVA for repeated measures was employed. The prediction was supported for verbalizers, $F(1,5)=18.75$, p .01 , and approached significance at the .01 level for imagers, $F(1,8)$ $=10.583$. A second prediction, that imagers would perform better than 
verbalizers on trial II, was tested using a t-test for independent means. The results did not support the expected difference in performance between imagers and verbalizers on trial II, $t(13)=.487$. The third prediction, that verbalizers would perform better than imagers on trial III, was again tested using a t-test for independent means. The results were significant, $t(13)=2.63$, but not in the predicted direction. Rather, imagers performed significantly better than verbalizers on trial III. Means and standard deviations are presented in Table III.

\section{TABLE III}

MEANS AND STANDARD DEVIATIONS FOR IMAGERS AND VERBALIZERS ON TRIALS II AND III OF THE PAL TASK

\begin{tabular}{l|c|c|c|c|}
\hline \multirow{2}{*}{ Classification } & $\overline{\mathrm{X}}$ & SD & $\overline{\mathrm{X}}$ & Trial III \\
\cline { 2 - 5 } & 8.888 & 1.166 & 5.000 & 3.182 \\
Imagers & 8.666 & 1.033 & 3.666 & 3.204 \\
\hline
\end{tabular}

The last analysis concerns possible correlations between selfreport measures of imagery (Betts, Gordon, IPI) to rated vividness on the OMR reports. Reliability of the two judges' ratings on vividness was $.914(p<.001)$. Using Pearson's $\underline{r}$, it was found that OMR reports correlate significantly with the IPI scale of visual imagery $(\underline{r}=.815$, $\mathrm{df}=14, \mathrm{p}<.001)$. There was no correlation between OMR reported vividness and the Betts scale $(\underline{r}=.281$, df $=14)$, or the Gordon test $(\underline{r}=.065, \mathrm{df}=14)$. Means and standard deviations are presented in Table IV. 
TABLE IV

MEANS AND STANDARD DEVIATIONS FOR OMR, IPI, BETTS, AND GORDON

\begin{tabular}{c|c|c}
\hline \hline Measure & $\bar{X}$ & SD \\
\hline OMR & 1.856 & 0.499 \\
IPI & 37.750 & 7.576 \\
Betts & 87.373 & 21.216 \\
Gordon & 3.875 & 1.668 \\
\hline
\end{tabular}


CHAPTER VII

\section{DISCUSSION}

The lack of concordance between subjects' classification by type of report and classification by eye movement direction could be due to several factors. First, the eye movement classification was a difficult one to make from the EOG recordings. Only one channel of the physiograph was allotted to the two EOG electrodes in the present study. After completion of the study, a reference for Rechtschaffen and Kales (1968) was found which states that when specific information about direction and size of eye movement is required, at least two channels are necessary for recording eye movement. This is to eliminate confusion between eye movement potentials and other artifacts. Thus, judgments of direction of eye movement based on this study's EOG recordings might be inaccurate. For the purpose of conservation, paper speed was run at $1.0 \mathrm{~cm}$ per second, which is the minimal speed recommended by Rechtschaffen and Kales (1968). A higher speed, such as $2.0 \mathrm{~cm}$ per second, might yield a more reliable recording of direction of LEMs. Also, the 15-second interval was an arbitrarily chosen time interval in which to make eye movement judgments, and perhaps a shorter interval preceding the interruption would be more appropriate. It is possible, of course, that there is no significant correlation between the two measures. Paivio (1973) states that neither EEG recordings nor LEMs have been found to correlate consistently with imagery. Further 
research controlling for the above mentioned deficiencies in the apparatus and technique would be necessary before any conclusive statements could be made about classifying subjects according to verbal report measures as compared to physiological measures.

Another factor to be controlled for is sex of subject. An equal distribution of males to females would be useful in analyzing data from this research. Four males and 12 females were included in this study. The breakdown of males and females, classification by type of report, and classification by eye movement direction, appears in Table $V$.

\section{TABLE V}

BREAKDOWN OF MALES AND FEMALES ACCORDING TO CLASSIFICATIONS BY TYPE OF REPORT AND BY EYE MOVEMENT DIRECTION

\begin{tabular}{l|l|c|c}
\hline \hline Measure & Classification & Males & Females \\
\hline \multirow{2}{*}{ Report } & Imagers & 1 & 8 \\
& Verbalizers & 3 & 3 \\
& Mixed & 0 & 1 \\
\hline \multirow{2}{*}{ Eye Movement } & Left movers & 4 & 5 \\
& Right movers & 0 & 3 \\
& Mixed & 0 & 4 \\
\hline
\end{tabular}

Classification by type of report and classification by eye movement direction was consistent for $50 \%$ of the subjects (imagers/left movers and verbalizers/right movers). Three female subjects changed from the imager classification by type of report to the mixed classification by eye movement direction. This is consistent with previous research findings that females are not as frequently left movers or right movers when compared to males. Rather, they are more likely to move their eyes in both directions and thus be classified in the mixed 
group (Bakan, 1971). Due to this finding, some researchers are restricting their population to males. However, having an equal distribution of males to females might allow such trends to surface.

In reviewing Table $V$, it can be seen that three of the males classified by type of report as verbalizers changed to the left mover classification based on eye movement direction. This could be due to previously mentioned artifacts in the eye movement recording itself. Since males are stereotypically thought of as being more verbal, analytical, and logical, the first classification seems to present a more accurate classification. However, the left mover classification of the four males in this study might be an accurate representation. Further research using more precise measurements and a larger population of males is needed before any definitive statements can be made. Two of the female subjects also switched classification in opposite directions of each other, so that it is not obvious in the distribution of numbers in Table V.

The second hypothesis concerned the differential performance of imagers and verbalizers on trials II and III of the PAL task. Data from this study did not support the predictions that imagers would perform superior to verbalizers on trial II and that verbalizers would perform superior to imagers on trial III. Paivio (1971) summarizes that:

. . individual differences in symbolic abilities are manifested in performance differences when cues for the relevant reactions are not readily available in the stimulus situation but must be supplied by the subject. (p. 503)

Thus, the superiority of high imagery subjects manifests itself in their imaginal-associative reactions to abstract words, which are not ordinarily effective stimuli for image arousal. This is also true for 
imagery subjects involved in perceptual recognition of flashed stimuli, especially stimuli that are particularly relevant to their ability (i.e., pictures). On the other hand, subjects with high verbal ability show superiority under the impoverished stimulus conditions involved in tachistoscope recognition and when the stimulus words are relatively unfamiliar. The PAL task in the present study was not designed to accentuate these differences, which could be one reason for a lack of findings in the predicted direction.

However, this does not explain the apparent superiority of imagers over verbalizers on the abstract/verbal trial III. This finding would fit into Paivio's Dual Coding Hypothesis (1972). According to this hypothesis, high imagery conditions are so effective in learning and memory because they increase the probability that both imagery and verbal processes will play a mediational role in item retrieval. Thus, people who report vivid imagery can utilize a source of information not available to vague imagers. This implies that even if the verbal code is forgotten, the availability of imagery as an alternative mediator allows reconstruction of the target item. In this sense, the imager has two mediational systems potentially available, rather than one. This theory is speculative and is presented only as one of many possible explanations for the observed superior performance of the imagers over the verbalizers on trial III. It should be noted that the observed differences in performance might also be due to error in the initial classification of subjects as imagers and verbalizers.

The third finding was that the Betts and Gordon self-report measures do not correlate with spontaneous vividness as measured by the 
OMR, but that the IPI visual imagery scale does. Two comments relating to the IPI scale are necessary. First, the sample size in the present study is smaller than that typically used for normative data on the IPI scales. Second, the IPI scales are not typically used independent of one another for data analysis in that factor analytic studies have demonstrated high loadings on three factors (Singer \& Antrobus, 1972, 1963). Thus, any conclusions based on the IPI scale used in this manner must be tentative. With this in mind, possible explanations for the OMR correlation with IPI scales and lack of correlation with the Betts and Gordon will be explored. The main consideration is that this difference is due to the different nature of the measures themselves. This idea has been postulated by several researchers and will be reviewed in the following paragraph.

Paivio (1971) makes a conceptual distinction between two types of imagery ability: one tied closely to perception and short-term memory for concrete events, and the other tied closely to words as conditional stimuli for memory images. This distinction was supported by Paivio and Roger's factor-analytic study in which the spatial ability and the verbal tests of imagery defined different factors (Paivio, 1971). This distinction is similar to one made by Neisser (as cited in Paivio, 1971) who discriminates between imagery as a process that represents spatial information effectively and imagery as a subjective (verbally reported) experience whose vividness may be unrelated to its usefulness or accuracy. In another factor-analytic study of imagery tests, it was suggested that introspective reports and objective tests of imagery cannot be used to substitute for one another: objective tests provide 
measures of abilities that may be quite different from those provided by introspective reports (DiVesta, Ingerso11, \& Sunshine, 1971). Starker (1974) evaluated how the active, volitional, imagery mode (as measured by the Betts and by visual imagery in response to stimulus words) related to the passive, spontaneous experience of imagery (as measured by the IPI vividness scale and by dream recal1). Results of the study demonstrated a consistency within the two modes of imagery in terms of vividness. However, the relationship between imagery modes was less clear, showing a real difference but allowing for some overlap. Starker (1974) suggests that the active/volitional and passive/spontaneous imagery modes are experienced differentially and are likely to follow different dynamic laws.

Although these researchers use different terminology, they are all making an important basic distinction between different types of imagery. This distinction can be further applied to the present study. The Betts and the Gordon direct a subject to image a certain object, and thus measure vividness of imagery of a volitional nature formed on demand. The IPI visual imagery scale simply inquires into a subject's everyday imagery, and is thus a measure of naturally occurring, spontaneous imagery. The IPI scale is therefore more closely related to a spontaneous report of imagery as measured by the OMR. The Betts and Gordon could very well be measuring another aspect of the imagery process, which would explain their lack of correlation with spontaneous imagery measures. 
CHAPTER VIII

\section{IMPLICATIONS FOR FUTURE RESEARCH}

This study has highlighted several implications for future research. The present study could be divided into two projects:

(1) classification of subjects as imagers or verbalizers by several different measures, and (2) a validity study of several different measures of visual imagery.

The first study would involve classifying subjects as imagers or verbalizers on the basis of OMRs, and comparing that classification with the EOG measure of direction of eye movement (utilizing two channels of the physiograph, increased paper speed, etc.). Several OMR sessions should be scheduled at different times during the day. The questionnaire which appears in Appendix $C$ should be developed specifically for the purpose of judging mentation reports as either perceptual or conceptual. Future research might also include olfactory, kinesthetic, and other imagery modes. An additional measure which differentiates imaginal and verbal habits and abilities, such as Paivio and Roger's questionnaire (Paivio, 1971), might also prove useful. This type of measure, which probes into a subject's everyday mentation, should yield consistent results with the OMR, which measures spontaneous, ongoing mentation.

A second study could then involve different types of measurements for imagery ability. It was concluded in the present study that the 
Betts and Gordon questionnaires were tapping different aspects of the imagery process than were the IPI visual imagery scale and the OMR. This distinction is important for future research in the area of imagery, as one measurement cannot necessarily be substituted for another. This finding is especially relevant when comparing the results of different studies involving measurements of imagery processes. Future research should concentrate on delineating between the various measurements involving imagery. 
REFERENCES 


\section{REFERENCES}

Bakan, P. The eyes have it. Psychology Today, 1971, 4, 64-68.

Bijou, S. W. \& Kenney, D. T. The ambiguity of TAT cards. Journal of Consulting Psychology, 1951, 15, 203-209.

Bogen, J. E. The other side of the brain: An appositional mind. Bulletin of the Los Angeles Neurological Societies, 1969, 34, $135-162$.

Bower, G. H. Analysis of a mnemonic device. American Scientist, 1970, 58, 496-510.

Bower, G. H. Mental imagery and associative learning. In L. Gregg (Ed.), Cognition in Learning and Memory. New York: Wiley, 1972.

Brooks, L. R. Spatial and verbal components of the act of recall. Canadian Journal of Experimental Psychology, 1968, 22, 349-368.

Corballis, M. \& Beale, I. The Psychology of Left and Right. Hillsdale, New Jersey: Lawrence Erlbaum Associates, 1976.

Day, M. E. An eye movement indicator of individual differences in the physiological organization of attentional processes and anxiety. The Journal of Psychology, 1967, 66, 51-62.

Deikman, A. J. Bimodal consciousness. Archives of General Psychiatry, $1971,25,481-489$.

Divesta, F. J., Ingersoll, G., \& Sunshine, P. A factor analysis of imagery tests. Journal of Verbal Learning and Verbal Behavior, $1971,10,471-479$.

Doob, L. W. The ubiquitous appearance of images. In P. W. Sheehan (Ed.), The Nature and Function of Imagery. New York: Academic Press, 1972.

Earnest, C. H. \& Paivio, A. Imagery ability in paired-associate and incidental learning. Psychnomic Science, 1969, 15, 181-182.

Edney, C. A comparison of three measures of waking fantasy. Unpublished master's thesis, Portland State University, 1980.

Eron, L. D. A normative study of the Thematic Apperception Test. Psychological Monographs, 1950,64 (Whole No. 315). 
Foulkes, D. Dream-like Fantasy Scale; A rating manual. Psychophysiology, $1971, \underline{1}, 335-336$.

Foulkes, D. \& Fleisher, S. Mental activity in relaxed wakefulness. Journal of Abnormal Psychology, 1975, 84, (1), 66-75.

Foulkes, D., Spear, P. S., \& Symonds, J. D. Individual differences in mental activity at sleep onset. Journal of Abnormal Psychology, $1965, \underline{70},(4), 231-243$.

Gazzaniga, M. A. \& Sperry, R. W. Language after section of the cerebral commissures. Brain, 1967, 90, 131-148.

Harnard, S. R. Creativity, lateral saccades, and the nondominant hemisphere. Perceptual and Motor Skills, 1972, 34, 653-654.

Huba, G. J., Segal, B., \& Singer, J. L. Consistency of daydreaming styles across samples of college male and female drug and alcohol users. Journal of Abnormal Psychology, 1977, 86, No. 1, 99-102.

Hyman, R. \& Anderson, B. Solving problems. Internation Science and Technology, 1956, 39, 75-97.

Jaynes, J. The Origin of Consciousness in the Breakdown of the Bicameral Mind. Boston: Houghton Mifflin Co., 1976.

Kimura, D. Asymmetries in perception related to hemispheric differentiation. In M. Kinsbourne (Ed.), Hemispheric Asymmetry of Function. London: Tavistock, 1973.

Kinsbourne, M. The control of attention by interaction between the cerebral hemispheres. In S. Kornblum (Ed.), Attention and Performance IV. New York: Academic Press, 1972.

Klinger, E. Structure and Function of Fantasy. New York: WileyInterscience, 1971 .

Kocel, K., Galin, D., Ornstein, R., \& Merrin, E. Lateral eye movement and cognitive mode. Psychonomic Science, 1972, 27, (4), 223-224.

Ludwig, A. M. Altered states of consciousness. In C. Tart (Ed.), Altered States of Consciousness. New York: John Wiley \& Sons, Inc. , 1972.

Meskin, B. B. \& Singer, S. L. Daydreaming, reflective thought, and laterality of eye movements. Journal of Personal and Social Psychology, 1974, 30, 64-71.

Milner, B. Visual recognition and recall after right temporal-lobe excision in man. Neuropsychologia, 1968, 6 , 191-209. 
Nebes, R. D. Direct examination of cognitive function in the right and left hemispheres. In M. Kinsbourne (Ed.), Asymmetrical Function of the Brain. New York: Cambridge University Press, 1978, 99-137.

Nebes, R. D. Hemisphere specialization in commissurotomized man. Psychological Bulletin, 1974, 81, 1-12.

Neisser, U. Cognitive Psychology. New York: Appleton, 1967.

Neisser, U. Changing conceptions of imagery. In P. Sheehan (Ed.), The Nature and Function of Imagery. New York: Academic Press, 1972 .

Ornstein, R. The Psychology of Consciousness. New York: Harcourt, 1972.

Paivio, A. Abstractness, imagery, and meaningfulness in paired associate learning. Journal of Verbal Learning and Verbal Behavior, $1965, \underline{4}, 32-38$.

Paivio, A. Paired associate learning and free recall of nouns as a function of concreteness, specificity, imagery, and meaningfulness. Psychological Reports, 1967, 20, 239-243.

Paivio, A. Effects of imagery instructions and concreteness of memory pegs in a mnemonic system. Proceedings of the 76 th Annual Convention of the American Psychology Association, 1968, $3,77-78$.

Paivio, A. Imagery and language. In S. J. Segal (Ed.), Imagery: Current Cognitive Approaches. New York: Academic Press, 1971.

Paivio, A. Imagery and Verbal Processes. New York: Holt, Rinehart, \& Winston, 1971b.

Paivio, A. A theoretical analysis of the role of imagery in learning and memory. In P. Sheehan (Ed.), The Nature and Function of Imagery. New York: Academic Press, 1972.

Paivio, A. Psychophysiological correlates of imagery. In F. J. Guivan \& R. Schoonover (Eds.), The Psychophysiology of Thinking. New York: Academic Press, 1973.

Paivio, A. Imagery and long term memory. In A. Kennedy \& A. Wilkes (Eds.), Studies in Long Term Memory. New York: John Wiley \& Sons, 1975 .

Paivio, A. \& Csapo, K. Concrete-image and verbal memory codes. Journal of Experimental Psychology, 1969, 80, 279-285. 
Paivio, A. \& Foth, D. Imaginal and verbal mediators and noun concreteness in paired-associate learning: The elusive interaction. Journal of Verbal Learning and Verbal Behavior, 1970, 9, 384-390.

Paivio, A. \& Madigan, S. A. Imagery and association value in paired associate learning. Journal of Experimental Psychology, 1968, 76, 35-39.

Paivio, A. \& Yuille, J. C. Changes in associative strategies and paired associate learning over trials as a function of word imagery and type of learning set. Journal of Experimental Psychology, 1969, 79, 458-463.

Paivio, A., Yuille, J. C., \& Madigan, S. A. Concreteness, imagery, and meaningfulness values for 925 nouns. Journal of Experimental Psychology Monograph, 1968, 76, (1), 1-25.

Pylyshyn, Z. W. What the mind's eye tells the mind's brain: A critique of mental imagery. Psychology Bulletin, 1973, 80, (1), 1-24.

Rechtschaffen, A. \& Kales, A. (Eds.). A manual of standardized terminology, techniques and scoring systems for sleep stages of human subjects. National Institute of Health Publication \#204, Washington, D.C.: U. S. Government Printing Office, 1968.

Richardson, A. Mental Imagery. London: Routledge \& Kegan Paul, 1969.

Richardson, A. Voluntary control of the memory image. In P. Sheehan (Ed.), The Nature and Function of Imagery. New York: Academic Press, 1972.

Segal, S. J. \& Fusella, V. Imaging and perceiving in two sensory modalities. Paper presented at meetings of Eastern Psychological Association, Philadelphia, 1969.

Sheehan; P. W. Functional similarity of imaging to perceiving: Individual differences in vividness of imagery. Perceptual and Motor Skil1s, 1966, 23, 1011-1033.

Short, P. L. The objective study of mental imagery. British Journal of Psychology, 1953, 44, 38-51.

Singer, J. L. \& Antrobus, J. S. A factor-analytic study of daydreaming and conceptually related cognitive and personality variables. Perceptual and Motor Ski11s, 1963, .17, 187-209.

Singer, J. L. \& Antrobus, J. S. Daydreaming, imaginal processes and personality: A normative study. In P. W. Sheehan (Ed.); The Nature and Function of: Imagery. New York: Academic Press, T972. 
Short, P. L. \& Walters, W. G. The relationship between physiological variables and stereognosis EEG. Clinical Neurophysiology, 1954, $\underline{6}, 29-44$.

Sperry, R. W. Specialization of cerebral function in the surgically separated hemispheres. In F. J. McGuigan \& R. A. Schoonover (Eds.), The Psychophysiology of Thinking. New York: Academic Press, 1973.

Starker, S. Aspects of inner experience: Autokinesis, daydreaming, dream recall, and cognitive style. Perceptual and Motor Skilis, $1973,36,663-673$.

Starker, S. Daydreaming styles and nocturnal dreaming. Journal of Abnormal Psychology, 1974, 83, (1), 52-55.

Tart, C. T. (Ed.). Altered States of Consciousness. New York: John Wiley \& Sons, 1972 .

Thorndike, E. L. \& Lorge, T. The Teacher's Word Book of 30,000 Words. New York: Teachers' College, Columbia U., Bureau Publications, 1944.

Tomkins, S. S. Affect, Imagery, and Consciousness. Vol. I. New York: Springer, 1962 .

Voge1, G., Foulkes, D., \& Trosman, H. Ego functions and dreaming during sleep onset. Archives of General Psychiatry, 1966, 14, 238-248.

Yuille, J. C. A detailed examination of mediation in paired-associate learning. Memory and Cognition, 1973, 1, 333-342.

Yuille, J. C. \& Paivio, A. Imagery and verbal mediation instructions in paired-associate learning. Journal of Experimental Psychology, 1968, 78, (3), 436-441. 
APPENDICES 


\section{APPENDIX A}

\section{RATING SCALE FOR VIVIDNESS}

$0 \quad$ No content reported, feels mind was blank.

1 Conceptual content--"I was thinking about different shades of yellow, like a banana and a lemon are different yellows. I didn't really see the colors, I was just thinking about them being different."

2 Perceptual content, non-hallucinatory (subject knows that the image was not real)--"I was looking at a lemon and a banana and noticing the difference in shades of yellow. I knew that I was just making up these images, but it seemed easier to think about the yellow differences by imagining some examples."

3 Perceptual content, hallucinatory (subject believed, at the time of the experience, that the image was real)--"I was looking at a lemon and a banana and comparing the differences in shades of yellow. They seemed so real that I could reach out and touch them."

(This scale is adapated from the Dreamlike Fantasy Scale as it appears in Foulkes, Spear, and Symonds, 1966.) 
APPENDIX B

\section{ORIENTATION SCRIPT--OMR}

Our studies usually involve waking subjects up from a state of sleep and asking them to report mental experiences which occurred just prior to their arousal. Today you are being asked to serve in a study which is a waking control for these experiments. The difference is that we are asking you to relax, but stay awake, during the recording session.

As in nighttime studies, we will call you at various times during the recording period and ask you for an account of the mental experience passing through your mind before the experimenter's call. If you do not wish to report your thoughts for any reason, that's okay. Just tell the experimenter that you would rather not talk about the mental experience.

We do two kinds of sleep studies. One type involves comparing reports obtained from different stages of sleep, of which there are five...

(Experimenter describes the progression of sleep stages, NREM $1-4$, and REM.)

Since sleep stages are physiological events with a duration of many minutes, subjects' reports of their mental experiences do not have to be identified precisely as having occurred just before their awakening. Sometimes the thoughts cover several minutes, or long periods of time before the awakening, as in the report of a long, involved dream.

The other kind of sleep study attempts to correlate mental experiences with much more brief physiological events, like some quality of brain wave activity. In these studies, subjects are asked to try to recount only the very last mental experience they had before their awakening, since only that one could meaningfully be correlated with a physiological event which happened only a second or two before the awakening.

The present study is a control for both kinds of sleep study. Thus, when we call you name today and ask you for an account of your waking mental experiences, we want you to describe only the very last thing in your mind before you heard your name called. The experimenter will ask you a series of questions about that brief mental experience. After these questions, the experimenter will ask you to relate the thoughts which led up to the mental experience. Again, if you do not 
wish to talk about any thought, or any aspect of a thought, just tell the experimenter. She will not question you about this.

Since this is a control for sleep experiments, the interview we will use is the same one we use when subjects tell us their dreams. Thus, its questions may not always apply too well to the kinds of experiences you have when awake.

(This script is adapted from Foulkes and Fleisher, 1975.) 


\section{APPEIVIX C}

\section{INTERV IEW--OMR}

1. What was the very last thing going through your mind just before I called you?

2. Was it visual? What could you see? Were you simply seeing something without reflecting on it or were you actively thinking or reflecting about what you were seeing?

3. Was it auditory? What could you hear? Were you simply hearing something without reflecting on it or were you actively thinking or reflecting about what you were hearing?

4. Which type of imagery predominated, what you could see or what you could hear?

5. Did you have any feelings or emotions during this experience?

6. (Omitted for experiences not involving imagining, such as eyes-open perceptions or unfanciful thoughts) At the time you sensed these things, did you feel that they were really happening, or did you know at the time that these were just things that you were making up in your mind?

7. At the time you thought these things, were you aware that you were here in the laboratory, lying in your bed?

8. Did you feel like you were voluntarily controlling the nature of your thoughts in the sense that you could stop them if you wanted to, or was it more like they were just "happening" to you?

9. How well would you say that you can remember exactly what was happening just before I called you: very well, fairly well, or not too well at all?

10. Just before I called you, would you say that you were: awake and alert, awake and relaxed, awake but drowsy, drifting off to sleep, in light sleep, or in deep sleep?

11. What can you remember of the sequence of thoughts which led up to the brief mental experience you have just described?

(This questionnaire is adapted from Foulkes and Fleisher, 1975.) 


\section{APPENDIX D}

\section{PAL INSTRUCTIONS}

Trial I: This experiment is concerned with the learning of noun pairs. I will hold a $3^{\prime \prime} \times 5^{\prime \prime}$ card in front of you, as such. You are to read the two words that are typed on the card, and try to remember them. You will have 6 seconds to look at the card, then I will turn the card face down on the table, like this. There will be a 2-second break, then I will present the next card for 6 seconds, and so on until 10 cards have been presented. After all 10 cards have been presented, I will go back through and present the first word from each card that you saw, like this, and you will have 6 seconds to write the word-pair that went with the word you see on this card. You are to write your answer on the $3^{\prime \prime} \times 5^{\prime \prime}$ card in front of you. As soon as 6 seconds is up, I will call time and you are to turn over the top card, regardless of whether or not you have written an answer. You are not expected to remember all of the words. Just write down the ones that you do remember. Do you have any questions? Are you ready to begin?

Trial II: Now I am going to teach you a mnemonic device to help you remember each word-pair. What I want you to do is to form an image, or mental picture, of the two words you see on each card. For example, with this card you might form an image of cattle grazing in a meadow. Then when I present the card with just the word "cattle," you will bring the image to mind of cattle grazing in a meadow, and thus remember the word "meadow"...

Trial III: I am now going to teach you a different mnemonic device to help you remember each word pair. What I want you to do is to construct a sentence or phrase for each word-pair in which the two words are embedded and associated in some way. For example, with this card you might form a phrase such as "my mood is full of hope." Then when I present the card with just the word "mood," you would bring the phrase "my mood is full of hope" to mind, and then write "hope" as your answer...

Trial IV: This time I want you to remember the word-pairs in whatever manner is easiest for you... 


\section{APPENDIX E}

PAL WORD LIST

\section{Trial I}

hote 1 - ticket

house - potato

power - spirit

dream - memory clock - forest fault - genius pride - theory apple - street horse - flower truth - misery

\section{Trial III}

moment - opinion theory - impulse heaven - loyalty moral - silence origin - freedom belief - science advice - quality chance - thought shame - justice spirit - ability
Trial II

child - garden water - pencil dress - factory flood - college woman - library arrow - painter paper - machine table - village piano - officer shoes - diamond

Trial IV

truck - priest money - bullet charm - safety humor - method style - pledge month - trouble candy - window honor - hatred insect - hammer ocean - letter 


\section{APPENDIX $F$}

PAL QUESTIONNAIRE

1. How easy/difficult was this task for you?

$\begin{array}{rllllll}1 & 2 & 3 & 4 & 5 & 6 & \begin{array}{l}7 \\ \text { very } \\ \text { difficult }\end{array} \\ \text { easy } & & & & & & \end{array}$

2. How often did you use the imagery/verbal mediation to remember the word-pairs (applicable for Trials II and III, respectively)?

\begin{tabular}{|c|c|c|c|c|c|}
\hline $\begin{array}{r}1 \\
\text { none of } \\
\text { the pairs }\end{array}$ & 3 & 4 & 5 & 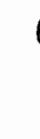 & 6 \\
\hline
\end{tabular}

Indicate how you remembered each of the word-pairs listed below...

Trial II: Please draw the image used to remember each of the word-pairs, if applicable. The quality of the drawing is unimportant; a brief sketch will be sufficient.

Trial III: Please write the verbal association used to remember each word-pair, if applicable.

(This questionnaire is adapted from Paivio, 1968.) 


\section{APPENDIX G}

\section{BETTS QUESTIONNAIRE}

Test Instructions. The aim of this test is to determine the vividness of your imagery. The items of the test will bring certain images to your mind. You are to rate the vividness of each image by reference to the accompanying rating scale, which is shown below. For example, if your image is "vague and dim," you give it a rating of 5 . Record your answer in the brackets provided after each item. Just write the appropriate number after each item. Before you turn to the items on the next page, familiarize yourself with the different categories on the rating scale. Throughout the test, refer to the rating scale when judging the vividness of each image. A copy of the rating scale will be printed on each page. Please do not turn to the next page until you have completed the items on the page you are doing, and do not turn back to check on other items you have done. Complete each page before moving on to the next page. Try to do each item separately independent of how you may have done other items.

The image aroused by an items of this test may be:

Perfectly clear and as vivid as the actual experience

Rating 1

Very clear and comparable in vividness to the actual experience

Rating 2

Moderately clear and vivid

Rating 3

Not clear or vivid, but recognizable

Rating 4

Vague and dim

Rating 5

So vague and dim as to be hardly discernible

Rating 6

No image present at all, you only "knowing" that you are thinking of the object

Rating 7

An example of an item on the test would be one which asked you to consider an image which comes to your mind's eye of a red apple. If your visual image was moderately clear and vivid you would check the rating scale and make " 3 " in the brackets as follows:
Item
$\underline{\text { Rating }}$
5. A red apple

Now turn to the next page when you have understood these instructions and begin the test. 
Think of some relative or friend whom you frequently see, considering carefully the picture that rises before your mind's eye.

Classify the images suggested by each of the following questions as indicated by the degrees of clearness and vividness specified on the Rating Scale.

Item

1. The exact contour of face, head, shoulders, and body

2. Characteristic poses of head, attitudes of body, etc.

3. The precise carriage, length of step, etc. in walking

4. The different colors worn in.some familiar costume

Rating

Think of seeing the following, considering carefully the picture which comes before your mind's eye; and classify the image suggested by the following question as indicated by the degree of clearness and vividness specified on the Rating Scale.

Item

Rating

5. The sun as it is sinking below the horizon

Think of each of the following sounds, considering carefully the image which comes to your mind's ear, and classify the images suggested by each of the following questions as indicated by the degrees of clearness and vividness specified on the Rating Scale.

Item

6. The whistle of a locomotive

7. The honk of an automobile

8. The mewing of a cat

9. The sound of escaping steam

10. The clapping of hands in applause

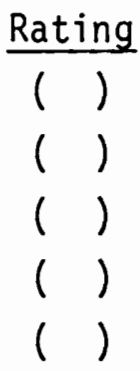

Think of "feeling" or touching each of the following, considering carefully the image which comes to your mind's touch, and classify the images suggested by each of the following questions as indicated by the degrees of clearness and vividness specified on the Rating Scale.

Item

11. Sand

$\underline{\text { Rating }}$

12. Linen

13. Fur

14. The prick of a pin

15. The warmth of a tepid bath 
Think of performing each of the following acts, considering carefully the image which comes to your mind's arms, legs, lips, etc., and classify the images suggested as indicated by the degree of clearness and vividness specified on the Rating Scale.

Item

Rating

16. Running upstairs

17. Springing across a gutter

18. Drawing a circle on paper

19. Reaching up to a high shelf

20. Kicking something out of your way

Think of tasting each of the following, considering carefully the image which comes to your mind's mouth, and classify the images suggested by each of the following questions as indicated by the degrees of clearness and vividness on the Rating Scale.

Item

$\underline{\text { Rating }}$

21. Salt

22. Granulated (white) sugar

23. Oranges

24. Jelly

25. Your favorite soup

Think of smelling each of the following, considering carefully the image which comes to your mind's nose, and classify the images suggested by each of the following questions as indicated by the degrees of clearness and vividness specified on the Rating Scale.

Item

26. An ill-ventilated room

27. Cooking cabbage

28. Roast beef

29. Fresh paint

30. New leather

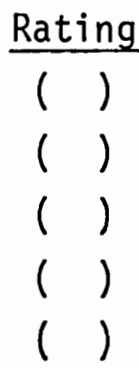

Think of each of the following sensations, considering carefully the image which comes before your mind, and classify the images suggested as indicated by the degrees of clearness and vividness specified on the Rating Scale. 
Item

$\underline{\text { Rating }}$

31. Fatigue

32. Hunger

33. A sore throat

34. Drowsiness

35. Repletion as from a very full meal

(This questionnaire appears in Richardson, 1969.) 


\section{APPENDIX $\mathrm{H}$}

\section{GORDON TEST}

The questions on this form are concerned with the ease with which you can control and manipulate mental images. For some people this task is relatively easy and for others relatively hard. One subject who could not manipulate his imagery easily gave this illustration. He visualized a table, one of whose legs suddenly began to collapse. He then tried to visualize another table with four solid legs, but found it impossible. The image of the first table with its collapsing leg persisted. Another subject reported that when he visualized a table, the image was rather vague and dim. He could visualize it briefly but it was difficult to retain by any voluntary effort. In both these illustrations the subjects had difficulty in controlling or manipulating their visual imagery. It is perhaps important to emphasize that these experiences are in no way abnormal and are as often reported as the controllable type of image.

Read each question, then close your eyes while you try to visualize the scene described. Record your answer by underlining "Yes," "No," or "Unsure," whichever is the most appropriate. Remember that your accurate and honest answer to these questions is most important for the validity of this study. If you have any doubts at all regarding the answer to a question, underline "Unsure." Please be certain that you answer each of the fourteen questions.

Can you see a batter standing at home plate waiting for the first pitch?

Yes No Unsure

Can you see the same man in the same place but now dressed in red bathing trunks?

Yes No Unsure

Can you hear an orchestra playing "God Bless America"?

Can you now hear it played by a single trumpet?

Yes No Unsure

Yes No Unsure

Can you feel the texture of an ordinary nailbrush rubbed across the tips of your fingers?

Yes No Unsure

Can you feel what it is like if the brush suddenly changes to a wire one?

Yes No Unsure 
Can you feel the movement of your muscles as you attempt to throw a baseball as far as you can?

Now, can you feel the same muscles as you throw the ball, very gently, to a small child?

Can you taste the strong, sour taste of a lemon?

Can you now add the flavor of white granulated sugar to that of the lemon?

You come into a freshly painted room. Can you smell the paint... it's strong and overpowering? Yes No Unsure Can you now smell the same room filled with the scent of lavender?

Can you feel yourself very sleepy, beginning to yawn, and unable to keep your eyes open?

Can you now feel yourself tingling with vitality, alert and ready for anything?

(This test is adapted from Richardson, 1972.)
Yes No Unsure

Yes No Unsure

Yes No Unsure

Yes No Unsure

Yes No Unsure

Yes No Unsure

Yes No Unsure 


\section{APPENDIX I}

\section{IPI SUBSCALES}

Scale 1 Daydreaming Frequency

Scale 2 Night-dreaming Frequency

Scale 3 Absorption in Daydreaming

Scale 4 Acceptance of Daydreaming

Scale 5 Positive Reactions to Daydreams

Scale 6 Frightened Reactions to Daydreams

Scale 7 Visual Imagery in Daydreams

Scale 8 Auditory Imagery in Daydreams

Scale 9 Problem-solving in Daydreams

Scale 10 Present Orientation in Daydreams

Scale 11 Future Orientation in Daydreams

Scale 12 Past Orientation in Daydreams

Scale 13 Bizarre Improbable Daydreams

Scale 14 Mind Wandering

Scale 15 Achievement-oriented Daydreams

Scale 16 Hallucinatory Vividness of Daydreams

Scale 17 Fear of Failure in Daydreams

Scale 18 Hostile Aggressive Daydreams

Scale 19 Sexual Daydreams

Scale 20 Heroic Daydreams

Scale 21 Guilt Daydreams

Scale 22 Interpersonal Curiosity

Scale 23 Impersonal-mechanical Curiosity

Scale 24 Boredom Susceptibility

Scale 25 Mentation Rate

Scale 26 Distractibility

Scale 27 Need for External Stimulation

Scale 28 Self-revelation

Taken from G. J. Huba, B. Segal, \& J. L. Singer, Consistency of daydreaming styles across samples of college male and female drug and alcohol users, Journal of Abnormal Psychology, 1977, 86, No. 1, 99-102. 